\title{
Smart Irrigation System using IoT
}

\author{
M Gayathri', D Arun Shunmugam², A Ishwariya ${ }^{3}$ \\ Assistant Professor ${ }^{1,3}$, Associate Professor ${ }^{2}$ \\ Department of Computer Science and Engineering, \\ PSR Engineering College
}

\begin{abstract}
In this work we use drip irrigation where the water was allowed to drip slowly to the roots of plant either from above the soil surface or buried into the surface so that the water can be placed directly into the root zone and minimize evaporation. It uses temperature sensor, soil humidity sensor to collect and monitor field information and also uses float switches to monitor ground water level through web page. When the field gets dry and ground water level falls down, it will be notified through SMS. This provides a solution for the problems in developing a smart farming system. It uses node MCU, relay and water pump.
\end{abstract}

\section{Keywords: IoT, Drip Irrigation}

\section{Introduction}

Agriculture plays a vital role in world-wide economy. It is the main source of sustenance for people. It is necessary to make economical utilization of resources as per the environmental conditions, to fulfill the fundamental needs of the crops. This work includes improvement in the previous work, here drip irrigation is used instead of normal irrigation method. It's been long since sensors were introduced in the agriculture operations. But the problem with the traditional approach of utilizing sensor technology was that we were not able to get the live data from the sensors. The sensors used to log the data into their attached memory and later on we were able to use it. To improve traditional methods, there has been many systems developed using advanced technologies that help to reduce crop wastes, prevent excessive and scarce watering to crops and thereby increase the crop yield. With the introduction of Industrial IoT in Agriculture, far more advanced sensors are being utilized. The sensors are now connected to the cloud via cellular/satellite network. Which lets us to know the real-time data from the sensors, making decision making effective. The applications of IoT in the agriculture industry has helped the farmers to monitor the water tank levels in real-time which makes the irrigation process more efficient. The advancement of IoT technology in agriculture operations has brought the use of sensors in every step of the farming process like how much time and resources a seed takes to become a fully-grown vegetable.

\section{Drip Irrigation using IoT}

Automation in irrigation helps to improve efficient Drip in low-pressure, low-volume irrigation. The water is usually carried through polyethylene tubing, and is applied directly to the root zone of the plants. Efficient irrigation systems require the selection of an appropriate method for the crop being grown, adequate monitoring of the irrigation system and of water delivery, and appropriate application rates depending on the growth stage of the crop. The important parameters to be measured for automation of irrigation system are soil moisture and temperature. The entire field is first divided in to small sections such that each section should contain moisture sensor and a temperature sensor. Advantages of drip irrigation systems as compared to overhead sprinkler systems include reduced water use, reduced erosion and runoff potentials, and decreased weed growth.

\section{System Modeling and Design}

\section{Existing System}

In the previous existing method agriculture process is automated using IoT. In that work low cost soil moisture sensors, temperature sensors, Wi-Fi module is used. They continuously monitor the field and send it to the web server using transmitter. The sensor data are stored in database. The web application is designed in such a way to analyze the data received and to check with the threshold values of moisture and temperature. The decision making is done at server to automate irrigation. If soil moisture is less than the threshold value the motor is switched ON and if the soil moisture exceeds the threshold value the motor is switched Off. This method can also be used in green houses where in addition light intensity control can also be controlled and automated. The highlighting features are web interface-based processor, and increased durable soil humidity sensor. It proposes low cost and wireless sensors to acquire the soil moisture and temperature from farm locations. Though there are sensors collecting field information's the water level should also be monitored and should be notified when there is a fall in water level of the water source.

\section{Proposed System}

In the proposed system instead of normal irrigation type we use drip irrigation method where the water can be directed to the root in sufficient amount so that water as well crop management can be improved. Using IoT the drip irrigation method is automated with the help of sensors and pipe tubes. Various sensors such as temperature, soil moisture sensors are used in field monitoring and the ground water level can be monitored lively using the float switch where the fall in water level can be notified to the farmer through SMS. If the field is dry it can also be notified to the farmer to his mobile and the motor will be switched ON and if the moisture level attains a certain level the motor is switched OFF automatically without manual instruction. The farmer can monitor the field and water level either through the web page which updates field information lively or through SMS in mobile phone. Thus, through the Web interfaced processor and relay switches the water management is controlled and information is delivered to the user. 


\section{Architecture Description}

The block diagram given below describes the sensors connected to the node MCU which is a software embedded microprocessor which controls the sensors and delivers the information from the sensors to the web page. The node MCU and relay are connected to the power supply and motor is connected with relay for automatic ON/OFF.

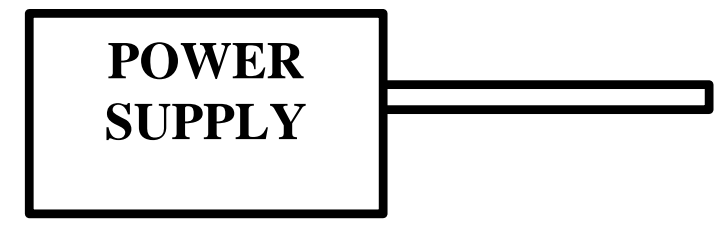

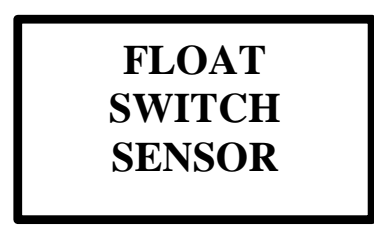
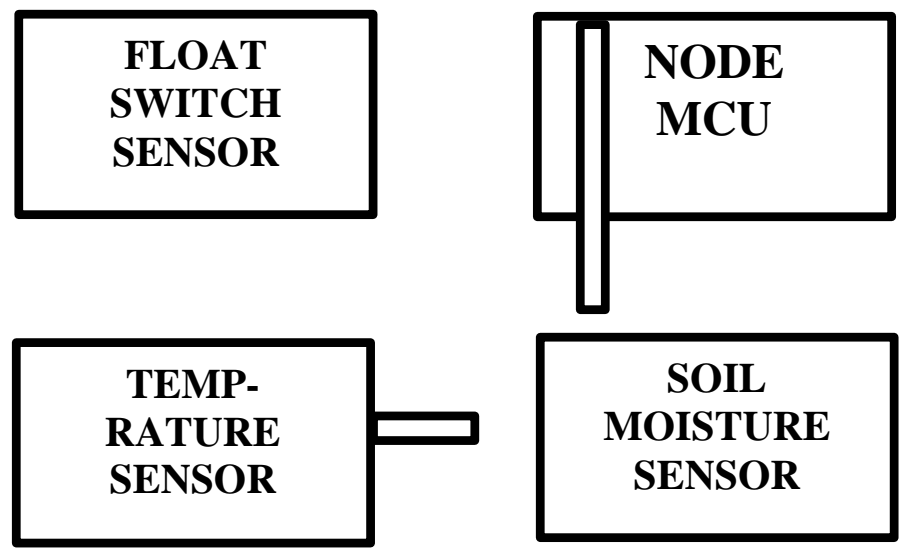

MOTOR

PUMP

Fig. : Block Diagram for System Design

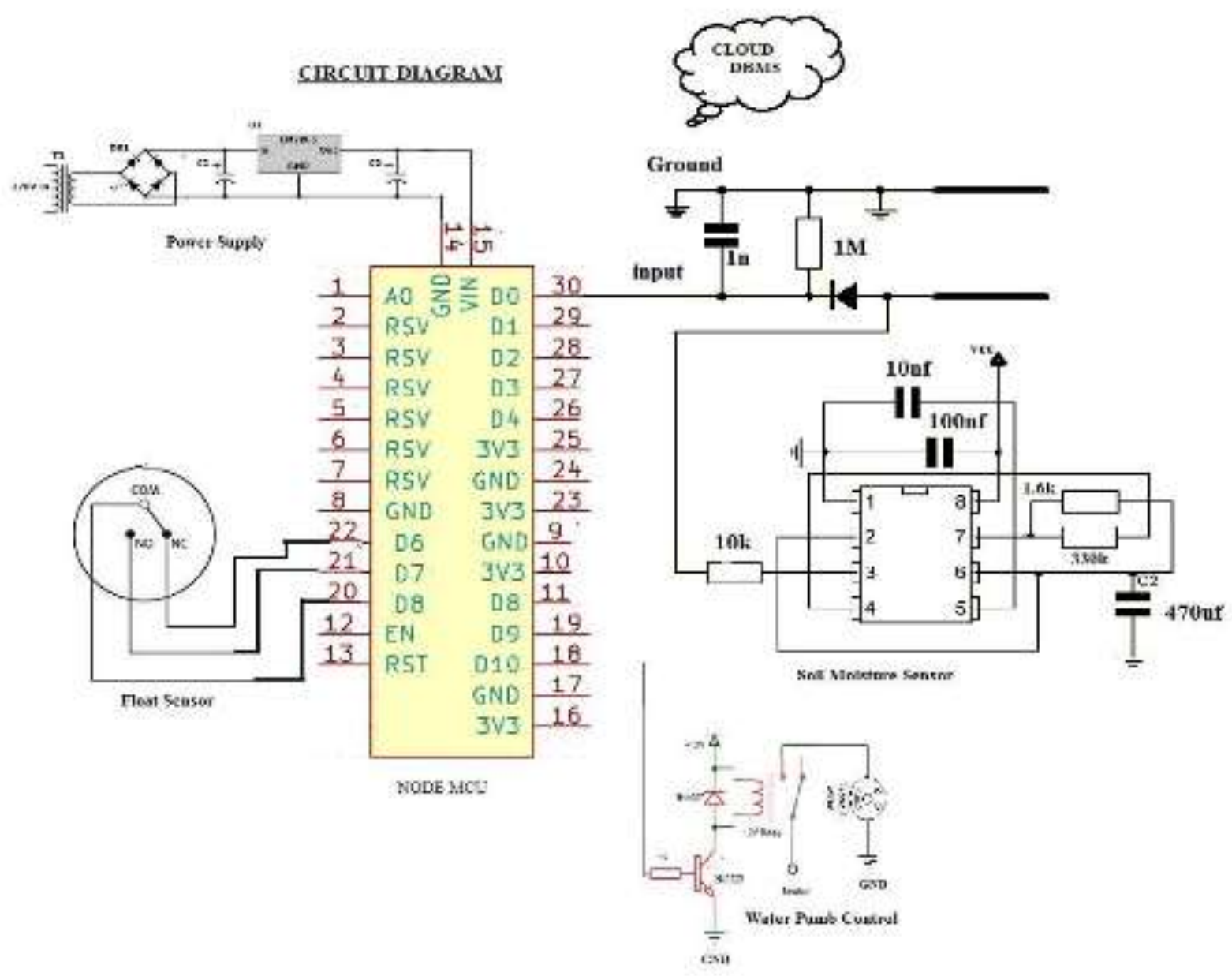

Fig. : Circuit Diagram of System 
The fig 4.2 show the circuit connection of system where the microcontroller is embedded with software code and the float sensor along with water pump control is connected to the node MCU and the soil moisture sensor is grounded in soil which collects the soil moisture attributes and sends soil information to the microcontroller which can be stored in the cloud storage.

\section{Implementation}

\section{Drip Irrigation Automation}

In drip irrigation systems, pump and valves may be manually or automatically operated by a controller. Most large drip irrigation systems employ some type of filter to prevent clogging of the small emitter flow path by small waterborne particles. New technologies are now being offered that minimize clogging.

Drip and subsurface drip irrigation is used almost exclusively when using recycled municipal wastewater. Regulations typically do not permit spraying water through the air that has not been fully treated to potable water standards. Because of the way the water is applied in a drip system, traditional surface applications of timed-release fertilizer are sometimes ineffective, so drip systems often mix liquid fertilizer with the irrigation water. An emitting pipe is a type of drip irrigation tubing with emitters pre-installed at the factory with specific distance and flow per hour as per crop distance. An emitter restricts water flow passage through it, thus creating head loss required (to the extent of atmospheric pressure) in order to emit water in the form of droplets. This head loss is achieved by friction/turbulence within the emitter.

The soil moisture sensors are placed at every few feet with the probes in the ground. The soil moisture sensor is set to a particular level based on the type of soil and the crops being grown. The soil moisture is checked through the sensor. The sensors value is then sent to the NodeMCU or the Wi-Fi module. Since this acts like an arduino but can be connected to the Wi-Fi, the sensor reading are checked and matched to the set value of reading. If the value of the soil moisture sensor is equal to the set value, then a command is sent to the relay to switch OFF the motor. A message is then sent to the client's mobile which is connected to the Node. If the moisture of the soil is less, then the Node MCU sends a command to the relay to turn ON the motor.

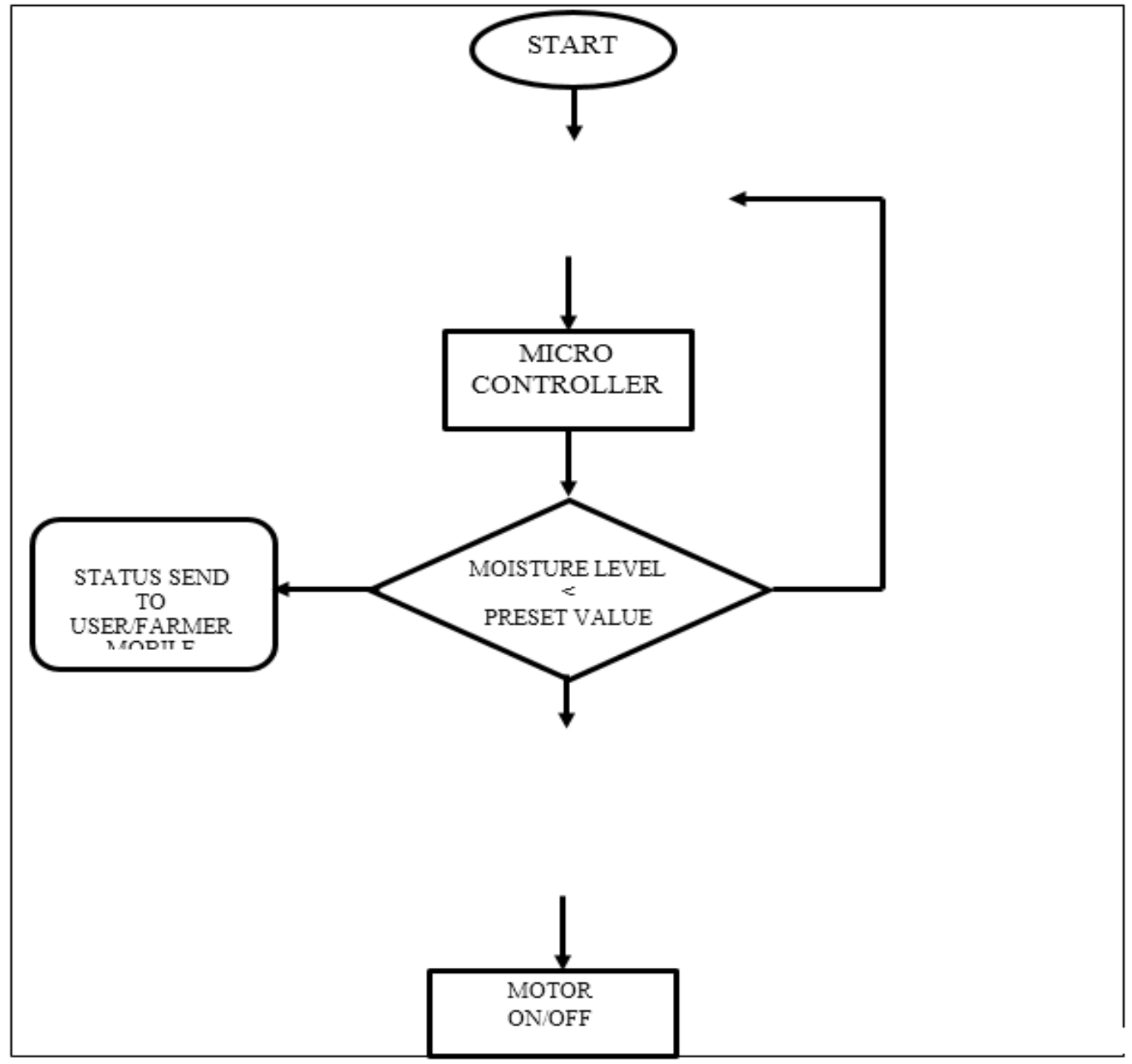

Fig. : Flow Diagram of the Proposed System 
When the water is opened, the drip irrigation system starts to drip the water at the roots. It allows water for half an hour and after half an hour; the moisture level is again checked and sent to the Node MCU. A message is sent to the client device saying that the plants have been watered at that particular time. The process then repeats all over. The intention of this project is to provide the user far away from the fields, a chance to keep an eye on their plants.

\section{Sensor Implementation}

The system involves three layers of operations, namely, sensor layer, transport layer, application layer. Their functions are as follows:

- Sensor/Information Collection Layer: The main task of this layer is to achieve automatic and real-time transformation of the physical figures of real-world agricultural production into digital information or data that can be processed in virtual world through various means.

The main task of Information collection layer is to mark the various kinds of information, and collect the marked information and the physical information in the real world by sensing techniques, and then transform them to digital information for processing. Information collection layer involves these techniques: two-dimension code labels and readers, RFID tags and readers, cameras, GPS sensors, terminals, cable networks, sensor networks and wireless networks

- Transport/Network Layer: The main task of this layer is to collect and summarize the agricultural information acquired through Sensor Layer for processing. Transport Layer is the nerve centre and cerebra of Internet of Things for Agriculture, transmitting and processing data. The network layer includes the integration of the Internet network and telecommunication, network management centre, information centre and intelligent processing centres.

- Application Layer: The main task of this layer is to analyze and process the information collected so as to cultivate digital awareness of the real word. It is a combination of IoT and Agricultural Market intelligence.

\section{Results}

The below screenshot is the web page design of the system where the home page contains the project details and the developer details with the link word as "Get in!". By clicking on the "Get in!" link one can enter into the next page where the sensor information of the field will be displayed.

\section{SMART IRRIGATION SYSTEM USING IOT}

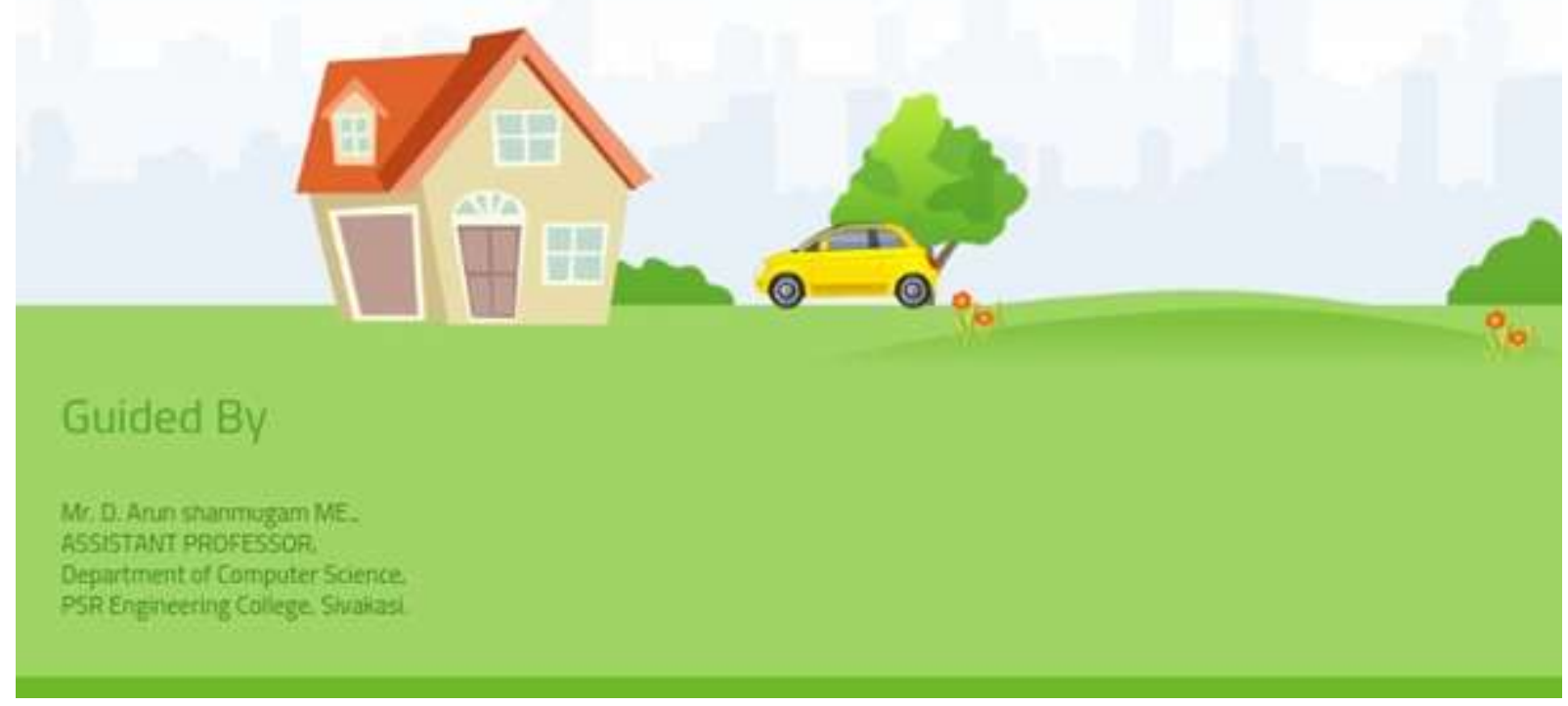

Fig. Webpage Design 
The above screenshot is the web page design of the system where the home page contains the project details and the developer details with the link word as "Get in!". By clicking on the "Get in!" link one can enter into the next page where the sensor information of the field will be displayed. The "Get in!" link provided in the home age will direct through the next age which contains live monitoring information about the field. Using the mobile hotspot with the specified user name and password in the hardware embedded code any mobile or system can access the field information.

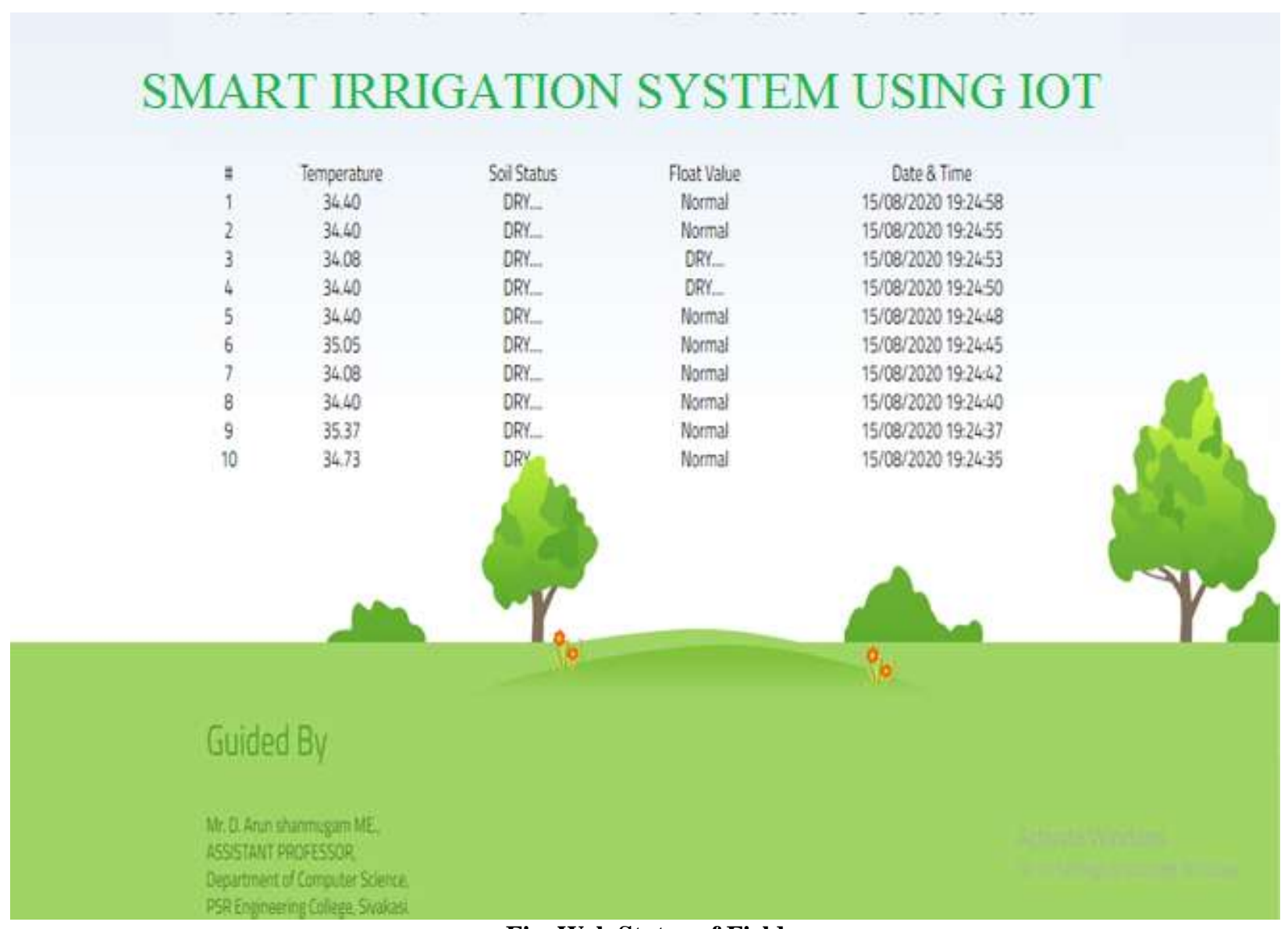

Fig. Web Status of Field

The above screen displays the field information that is monitored lively using cloud can be provided in the table format. The details include temperature of the field where the temperature sensor in the field provides field environmental temperature through the WiFi module and the web page access the updated information from cloud.

The Soil status displays of the condition of the soil whether it is dry or normal if it is dry then the water pump will be switched ON and the water will be pumped as drips into the field through the pipelets near the crops over the field. when the level reaches the threshold value it will be turned OFF and if it is normal then the water pump will be stopped. Both the soil and temperature sensor provides the timing condition of the field and the time will also be displayed in the web page so that one could monitor and gather information about the status of field at any time.

The Ground water level i.e., float value which notifies the sufficient water level in the water source for example well. When the ground water level drops less than the sufficient water level which is needed to supply to the field efficiently then the notification is send to the user mobile through SMS offline and he can further check the details in the web page online with the exact date and time

It is simple yet useful system where it will increase the proper maintenance of the field using IoT technology the farmer or the user can monitor the information of the soil which is main source of agriculture and water is provided based on the condition of the field and the temperature can also be monitored so that the farmer can decide what type of crop can be planted and what will be outcome based on their experience.

\section{Conclusion}

Drip irrigation automation with live monitoring has been proposed using Wi-Fi module and Cloud Computing, The System has high efficiency and accuracy in fetching the live data of fields such as soil moisture level and temperature including the ground water level. Whether it is online or offline the notification for the ground water level drop can be notified through mobile or system. This system has also improved the normal agricultural irrigation process by using drip irrigation which is used in less water wastage. 


\section{Future Scope}

Future work could be focused more on increasing sensors on this system to fetch more data especially with regard to Pest Control and by also integrating GPS module in this system to enhance this Agriculture IoT Technology to full-fledged Agriculture Precision ready product. Even though the proposed work can be applied in real time it can be enhanced by developing this system for large acres of land. Also the system can be integrated to check the quality of the soil and the growth of crop in each soil.

\section{References}

[1] Meghana Gupta Arakere, Avik Seal and Tejomurthula Bhuvana Teja "“SMART IRRIGATION SYSTEM USING IOT”, Asian Journal of Science and Technology, June 2019.

[2] Tyson Baptist Dcunha, “AUTOMATED IRRIGATION SYSTEM USING IOT”, International Journal of Engineering Research and Technology (IJERT), May 2019.

[3] Tigist Hilemariam Senbetu, Kishore kumar k, G.M. Karpura Dheepan, "IOT BASED IRRIGATION REMOTE REAL-TIME MONITORING AND CONTROLLING SYSTEMS", International Journal of Innovative Technology and Exploring Engineering (IJITEE), May 2019.

[4] AisyahRahmaKholifah, Kelvin IslamiAlbarSarosa, Moechammad Sasrosa, "DRIP DRIP IRRIGATION SYSTEM BASED ON INTERNET OF THINGS (IOT) USING SOLAR PANEL ENERGY", 2019 Fourth International Conference on Informatics and Computing (ICIC).

[5] Chiyurl Y.; Miyoung H.; Changkyu L. SWAMP: “Implement Smart Farm with IoT Technology". In Proceedings of the International Conference on Advanced Communications Technology (ICACT), Chuncheon-si,Gangwon-do, Korea, 11-14 February 2018.

[6] Nandan N, Dr. K. Thippeswamy, “A SECURE INTELLIGENT DRIP IRRIGATION SYSTEM USING IOT, CLOUD, MOBILE APPLICATION”, International Research Journal of Engineering and Technology (IRJET), March 2018. 